\title{
A educação popular e a vocação ontológica do ser mais: um estudo da trajetória de Carlos Rodrigues Brandão na Universidade
}

\author{
Popular Education and Calling Being Ontological More: \\ a Carlos Path Study Rodrigues Brandão at University
}

Fernanda dos Santos Paulo'

Jaime José Zitkoski

\section{RESUMO}

O artigo descreve e analisa concisamente, à luz do referencial freiriano, a trajetória do professor Carlos Rodrigues Brandão na defesa da Educação Popular, sobretudo no tocante a vocação ontológica do ser mais, termo utilizado por Paulo Freire em Pedagogia do Oprimido e Pedagogia da Esperança. A metodologia utilizada, além de uma pesquisa bibliográfica e o uso do Diário. O objetivo principal do texto é identificar elementos da vocação ontológica do ser mais na concepção de Educação Popular do educador, na sua trajetória teórico-prática na atuação enquanto professor e pesquisador na Universidade. Como resultado das pesquisas realizadas, constatamos a presença da práxis cotidiana na luta pela defesa de uma educação transformadora e humanizadora, seja na universidade ou fora dela.

\section{PALAVRAS-CHAVE}

Carlos Rodrigues Brandão; Educação Popular freiriana; Universidade.

1 Universidade do Vale do Rio dos Sinos.

2Universidade Federal do Rio Grande do Sul. 


\section{ABSTRACT}

The article describes and analyzes concisely, in the light of Freirian reference, the trajectory of Professor Carlos Rodrigues Brandão in defense of popular education, especially regarding the ontological vocation of more term used by Paulo Freire in Pedagogy of the Oppressed and Hope Education. The methodology used, as well as a literature search and use Daily. The text of the main objective is to identify elements of the ontological vocation of being more in the design of Popular Education of the educator in its theoretical and practical course in acting as a teacher and researcher at the University. As a result of research conducted, we found the presence of everyday practice in the struggle for the defense of a transforming and humanizing education, either at university or outside.

\section{KEY WORDS}

Carlos Rodrigues Brandão; Popular education freiriana; University. 


\section{1 - INTRODUÇÃO}

O artigo visa descrever e analisar de forma concisa, à luz do referencial freiriano, a trajetória do professor Carlos Rodrigues Brandão na universidade, sobretudo no tocante a sua defesa pela Educação Popular. Enfatizamos os elementos da sua trajetória teórico-prática que justificam a Educação Popular como vocação ontológica do ser mais (Freire, 1993;1994). Para a produção desse texto, utilizamos a pesquisa bibliográfica e registros em Diário de Campo ${ }^{1}$. Nosso maior objetivo é identificar elementos da vocação ontológica do ser mais desde a perspectiva freiriana na concepção de Educação Popular e a repercussão desta perspectiva na trajetória teórico-prática de Brandão.

A Educação Popular para o Brandão não significa apenas popularizar o acesso à educação, pois se faz indispensável à ideia de uma nova cultura popular como alternativa de trabalho político-pedagógico de transformação social. Se Brandão tem essa definição de Educação Popular e vem dialogando com o referencial freiriano, quais seriam os elementos fundantes dessa transformação?

\section{CARLOS RODRIGUES BRANDÃO: O PROFESSOR E O MILITANTE NA DEFESA DA EDUCAÇÃO POPULAR}

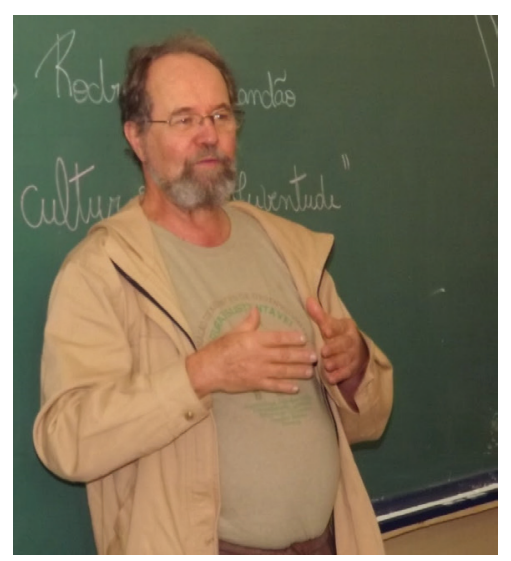

1 A autora realiza a sua pesquisa de doutoramento na Unisinos, e sob orientação do prof. Dro Danilo Streck e coorientação do prof. Dr ${ }^{\circ}$ Carlos Rodrigues Brandão sobre o tema s Pioneir@s da Educação Popular Freiriana que atuam na Universidade, sendo que o professor Brandão é um desses pioneiros. Os registros em Diário são frutos da pesquisa da doutoranda.
Carlos Rodrigues Brandão, nascido em 14 de abril de 1940 no Rio de janeiro, reconhecido pela participação militante nos movimentos de cultura popular a partir dos anos de 1960, considera-se como educador popular e antropólogo. Exerce a docência como profissão. Vem orientando trabalhos de mestrado e doutorado nas pesquisas com ênfase em antropologia camponesa, antropologia da religião, cultura popular, etnia e educação popular.

Tem doutorado em Ciências Sociais pela Universidade de São Paulo (1980) e atua como professor universitário desde a década de 1970, tendo a Cultura e Educação Popular como temas de pesquisa. Estudou Educação de Adultos no México em 1966, sendo uma de suas áreas de estudo.

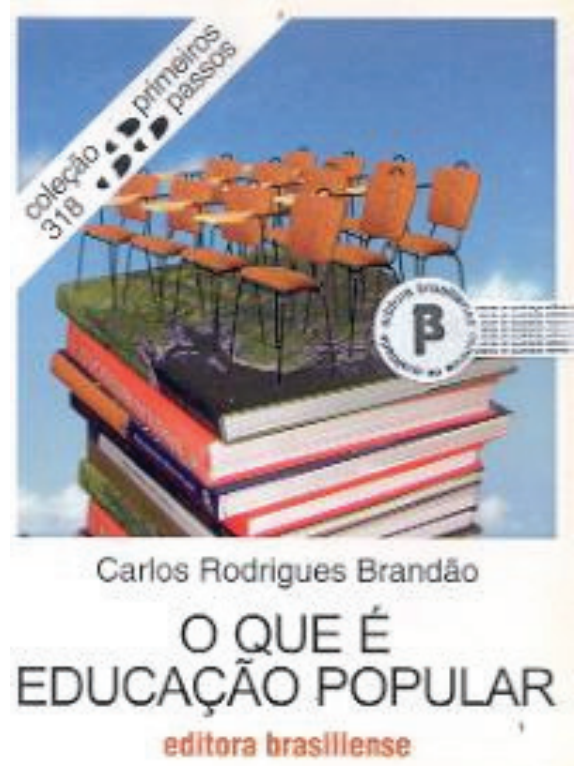

Morou em vários estados do Brasil, como Brasília, Goiás e São Paulo e já trabalhou como professor universitário em várias universidades brasileiras, dentre elas, na Faculdade de Educação da Universidade de Brasília e na Universidade Estadual de Campinas, já aposentado desde a década de 1990. Seus textos são, sobretudo, nas áreas de Antropologia e Educação, tendo dezenas de livros e artigos publicados acerca dos temas acima citados. Já, no campo da Educação, a ênfase de suas pesquisas e produções versa sobre Educação Popular. O educador carioca é, portanto, um andarilho do mundo e um militante apaixonado pela escrita, pela poesia, pela música e pela Educação e Cultura Popular. 


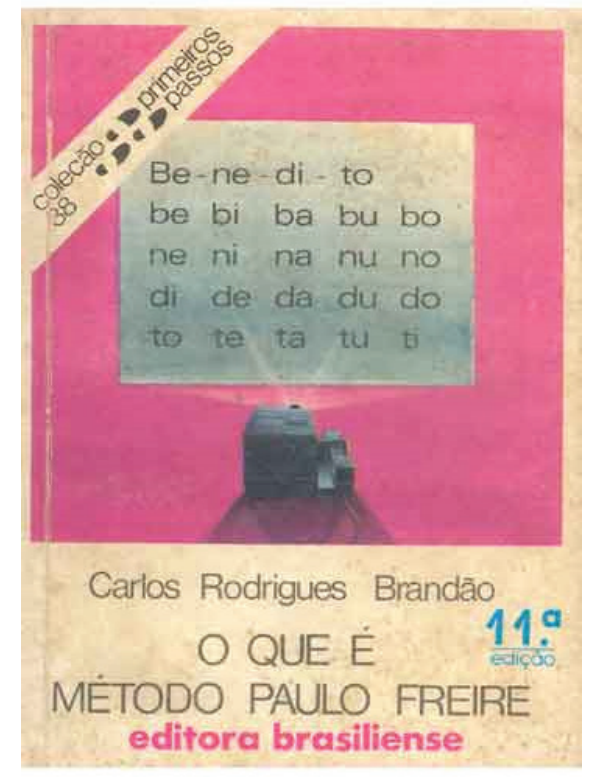

Carlos Rodrigues Brandão escreveu o livro, "O que é Método Paulo Freire" que apresenta a perspectiva e pressupostos teórico-metodológica do conceito de educação de Freire. Ele é um estudioso da obra de Paulo Freire, seu companheiro e amigo de lutas pela educação como prática da liberdade desde a década de 1970.

Possui uma trajetória profissional e militante construída por partilhas de experiências, seja através da escrita de livros e ou de rodas de conversas em universidades, escolas públicas e movimentos populares, como por exemplo, sua experiência no Movimento de Educação de Base. Entretanto, a sua andarilhagem pelo mundo não é marcada somente pelo trabalho universitário ao longo de sua trajetória docente em universidades do Brasil e da Europa, mas pelas experiências vividas e partilhadas em outros contextos escolares e não escolares.

A vocação para a humanização é vivenciada por Brandão a partir de sua concepção de Educação Popular. $\mathrm{O}$ educador tem sua trajetória marcada pelas lutas em prol da educação laica, popular e pública onde a desigualdade não persista ocupando o espaço da exclusão, defendendo portanto, uma Educação como Prática da Liberdade (Brandão, 1995; 2006). Segundo a proposta freiriana a Educação como Prática da Liberdade é característica da busca do ser mais enquanto vocação para a humanização ( Freire,
1994; Brandão, 2006). Essa é uma marca da trajetória docente do professor Carlos Rodrigues Brandão.

\section{OS ELEMENTOS FUNDANTES DA VOCAÇÃO PARA A HUMANIZAÇÃO SEGUNDO BRANDÃO}

Na trajetória de Brandão, ele vem dizendo e escrevendo a respeito da necessidade de práticas dialógicas na criação de mundos novos a ser construído pelos coletivos com o propósito de transformar o mundo. Com isto, o sonho, a esperança e a luta são necessários para a criação de um novo mundo. A busca do ser mais, vocação para a humanização é , deste modo, tarefa das pessoas. Assim, somos pessoas em permanente busca do ser mais, não só porque somos seres curiosos (Freire, 1993), mas porque sonhamos e lutamos pela conquista da nossa humanização e do mundo.

A educação transformadora, como vocação para a humanização, transforma a realidade com conscientização. A Educação Popular desde Paulo Freire entende a transformação como a busca de ser mais para a humanização das pessoas e do mundo. Para Brandão, o "projeto histórico de humanização libertadora através do trabalho político do povo" (2006, 56-57) revela que somos programados para ser mais ( Freire 1993;1994). Ou seja, "é por estarmos sendo assim que vimos nos vocacionando para a humanização e que temos, na desumanização, fato concreto na história, a distorção da vocação". (FREIRE, 1994, p. 99).

Carlos Rodrigues Brandão vem escrevendo acerca da Educação Popular não só como crítica a educação bancária (Freire,1993), mas porque seu argumento justifica a necessidade de uma educação com vocação transformadora. Na CONFITEA BRASIL $+6^{2}$, realizada em Brasília em abril de 2016, Brandão referencia a Educação Popular como uma educação revolucionária. Diz ele, que a Educação Popular tem

2 A autora esteve presente nesta Conferência e participou da mesa em que o Brandão fez a fala a cerca da Educação Popular, juntamente com Moacir Gadotti e Liana Borges. Saber mais ver em: http://fne.mec.gov.br/fne-noticias/1245-confintea-brasil-6-termina-com-balanco-positivo-de-discussoes Acesso: out,2016. 
um sentido e um significado que não é colonizador porque sua vocação é ser emancipatória. Um dos elementos dessa educação libertadora, revolucionária e emancipatória é a organização, a mobilização social e popular. Sem estas, para o Brandão (2006), não há transformação.

A organização e a mobilização são práticas fundamentais e necessárias para conhecer, problematizar e mudar a realidade social. Não é por acaso, que um dos elementos fundantes é a investigação dessa realidade de maneira participante. Portanto, a participação popular é um dos princípios da busca do ser mais.

Na trajetória de Brandão, a sua concepção político-educativa acerca da Educação Popular concebe a organização, a mobilização e a participação popular como meios de

produzir conhecimento de ação social, ou seja, que possam ser postos em prática na busca da vocação ontológica do ser mais para a humanização.

\section{4 - A EDUCAÇÃO POPULAR NA AMÉRICA LATINA SEGUNDO PARA BRANDÃO}

A Educação Popular caracteriza-se como um fenômeno sui-generis no contexto sociocultural latino-americano ${ }^{31}$ da segunda metade do século $X X$, mais exatamente nas décadas de 1950 e 1960. Produziram-se, nesse período, inúmeras experiências de Educação Popular, junto aos Movimentos de Cultura Popular e organização do povo pobre e oprimido, que resultaram em avanços significativos de conquistas sociais e políticas pelos setores marginalizados da população latino-americana. É nesse contexto histórico-cultural que a Educação Popular emergiu como um novo paradigma educacional, intimamente ligado às lutas de libertação dos povos latino-americanos, convergindo, assim, para a construção de uma nova hegemonia no interior da sociedade capitalista dependente (BRANDÃO, 1994).

$3^{1}$ Ressalva-se, contudo, que a Educação Popular não é, nos dias atuais, um fenômeno exclusivo da América Latina. Muito pelo contrário, existem experiências nesse campo em todos os continentes, principalmente nos países do $3^{\circ}$ Mundo, onde a realidade socioeconômica é muito cruel e impõe suas marcas de opressão com maior brutalidade. É nesse contexto que a Educação Popular encontra mais eco e contribui para o processo de libertação do povo oprimido.
O caminho construído pelos povos latino-americanos nesse período de grande efervescência política, experimentada desde a organização das classes populares, constitui-se em um exemplo teórico-prático para o mundo todo. A Educação Popular, então, passou a ser um modelo de luta contra-hegemônica dos oprimidos frente aos sistemas estruturados e defendidos a partir dos interesses da classe dominante em nível mundial.

Houve, a partir da experiência latino-americana, um verdadeiro intercâmbio de experiências de Educação Popular que enriqueceu o debate e as visões teóricas fundantes das atividades práticas de intervenção na realidade. As diversidades culturais, as realidades sociais distintas, as diferentes propostas de inserção social e política das classes populares, enfim, o caminho teórico-prático da Educação Popular foi sendo, dialeticamente, construído por todos os sujeitos que partilharam desse mesmo sonho e projeto de sociedade.

A rápida sistematização em relação aos conceitos aqui utilizados contribui para a compreensão analítica sobre a presença de elementos teórico-práticos da vocação ontológica do ser mais para a humanização no conceito de Educação Popular na perspectiva de Carlos Rodrigues Brandão.

A Educação Popular para Brandão (2006) "não é uma variante ou um desdobramento da educação de adultos" (p.41), tampouco uma "educação compensatória" (p.42). Ela "emerge como um movimento de trabalho político com as classes populares através da educação." ( p.42). Também, é considerada como um "trabalho simbólico e político de transformação da ordem social dominante" (p.44). Por isto o "lugar estratégico que funda a educação popular é o dos movimentos e centros de cultura popular: movimentos de cultura popular, centros populares de cultura, movimentos de educação de base, ação popular." ( BRANDÃO, 2006, p. 46).

Diante dessa breve conceitualização da Educação Popular para o educador carioca, podemos destacar alguns apontamentos acerca dos elementos que evidenciam a sua concepção aproximada da busca do ser mais em Paulo Freire (1993;1994).

Mesmo, o Brandão estando atuando há mais de quatro décadas na universidade, ele permanece dis- 
cutindo a Educação Popular em diferentes contextos educativos. A sua trajetória testemunha que o espaço das universidades é um lugar possível e importante para defender a Educação Popular enquanto método de trabalho, de educação libertadora e de projeto de transformação do sistema dominante ( Brandão, 2006).

Nos movimentos sociais populares, o educador vive, apresenta e revigora o sentido da Educação Popular enquanto instrumento de luta política através do trabalho com a classe popular (Diário, 2015;2016). É, mediante o trabalho libertador que vem realizando Carlos Rodrigues Brandão que constatamos a sua defesa pela Educação Popular, sobretudo no tocante a vocação ontológica do ser mais, termo utilizado por Paulo Freire em Pedagogia do Oprimido e Pedagogia da Esperança: Um Reecontro com a Pedagogia do Oprimido.

A vocação ontológica do ser mais é parte da nossa luta histórica pela libertação das amarras dominantes presentes numa sociedade desigual como a nossa. Freire $(1993 ; 1994)$ ao definir a vocação ontológica do ser humano, também defende a luta pela humanização compreendendo-a como algo concreto porque a situa num lugar, num tempo e em situações de desumanização. Para ele, nós não somos seres humanos vocacionados para ser menos, ou seja, não estamos sentenciados a vivermos numa realidade de desumanização. Essa concepção é presente na vida e obra de Carlos Rodrigues Brandão, principalmente quando ele propõe, por exemplo, a pesquisa participante como estratégia de organização, mobilização e participação da classe popular rumo a descolonização da vida.

A organização popular, elemento fundante da vocação ontológica do ser mais para a humanização, dá-se na escola e fora dela e busca alternativas práticas e críticas de romper com a educação desumanizadora. Já, o outro elemento, o da mobilização emerge da educação de classe, e pressupõe participação, comprometimento, formação crítica, politizadora e conscientizadora no processo de construção de um novo mundo.

Desse modo, asseguramos que, na/pela práxis de vida de Brandão, a sua definição de Educação Popular freiriana possui elementos fundantes que justifi- cam a necessidade da transformação social. Primeiramente, o reconhecimento da humanização e desumanização numa sociedade desigual. Se existe uma educação bancária de tendência excludente, se há pobres excluídos e miséria no mundo é porque há um projeto de sociedade dominador que defende uma realidade de desumanização. Diante desse contexto, é que Brandão, vem escrevendo e vivendo práticas alternativas de luta contra essa educação do ser menos, a qual é desumanizadora e funda-se no silêncio, na opressão, no medo, na violência e na exclusão. Por isto se faz necessário a produção da cultura da participação, pois a vocação do ser mais para a humanização só é possível porque sonhamos e somos seres aprendentes e desejamos a existência de um novo mundo em que as pessoas sejam comprometidas com o outro e com uma causa, a da humanização. Eis, aqui o destaque para a relevância da luta política e da esperança na construção de um novo mundo.

\section{UMA PALAVRA FINAL}

A descrição e análise da trajetória teórico-prática do educador popular e antropólogo Carlos Rodrigues Brandão nos revela que suas andanças pelo mundo vem deixando marcas de seu engajamento pela e com a Educação Popular freiriana. Freire continua sendo um dos referenciais teóricos de Brandão (Diário, 2016) porque contribui na concepção de Educação Popular enquanto instrumento de esperança, de lutas e de transformação do mundo. É, por isto um andarilho da organização e mobilização popular, um dos elementos fundantes da vocação ontológica do ser mais para a humanização. Sem organização não tem participação, mobilização e luta. Estes compõe o conjunto de elementos da busca do ser mais.

A vocação para a humanização em Brandão pressupõe lutar pelo ser mais ao lado da humanização do mundo. Isto posto, ele vem vivendo e construindo alternativas a educação do ser menos, revelando-nos que na universidade e fora dela é possível ir rompendo, de modo organizado, engajado e mobilizado, com as estruturas opressoras. Uma amostra de sua experiência é a prática de pesquisas partici- 
pantes. Ou seja, os elementos da vocação ontológica do ser mais na concepção de Educação Popular do Brandão, percebida e analisada através da sua trajetória teórico-prática são compreendidos na práxis cotidiana da sua luta em defesa de uma educação transformadora e humanizadora, seja na universidade ou fora dela.

Por tais razões é que a Educação Popular implica uma opção de classe e de projeto de educação e sociedade. Neste caso, a vocação ontológica do ser humano, presente na Educação Popular freiriana, é vivenciada na esperança e na luta permanente pela humanização. Os elementos identificados, portanto, são condições históricas e políticas da transformação social, cujo processo de conscientização é base importante na concepção de Educação Popular emancipatória e libertadora.

Nessa luta por libertação das classes populares, a Educação Popular está intrinsecamente presente enquanto potencial de formação cultural e política, educação para a cidadania, participação social, organização dos setores populares e reapropriação das conquistas já efetivadas. No bojo dos processos revolucionários - que visam a construir um novo projeto de sociedade - os Movimentos Populares, certamente, não dependem somente dos processos pedagógicos e/ou educativos (porque há outras instâncias do embate político, das estratégias mais imediatas que dão corpo e existência ao Movimento).

Mas, por outro lado, os movimentos sociais populares não têm muito tempo de vida se ignorarem o papel formativo e conscientizador das dimensões pedagógicas e educativas, quanto menos teriam fôlego para romper a ordem dominante e construir um novo projeto social sem o cuidado com a formação de lideranças e de uma nova cultura enquanto caminho para o exercício da cidadania e da vida democrática em sociedade. E, nesse contexto, Carlos Rodrigues Brandão é um dos inspiradores da trajetória de luta e engajamento político na /pela Educação Popular. 


\section{REFERÊNCIAS}

BRANDÃO, Carlos. O que é método Paulo Freire. Ed. Brasiliense, São Paulo, 1981. BRANDÃO, Carlos Rodrigues. Diário de campo - A Antropologia como Alegoria. São Paulo: Brasiliense, 1982.

BRANDÃO, Carlos Rodrigues. Os caminhos cruzados: formas de pensar e realizar a educação na América Latina. In: GADOTTI, M.; TORRES, C. A (Orgs). Educação popular: utopia latino-americana. São Paulo: Cortez, 1994.
BRANDÃO, Carlos Rodrigues. O que é educação. São Paulo: Brasiliense, 1995.

BRANDÃO, Carlos Rodrigues. O que é Educação Popular. São Paulo: Brasiliense, 2006.

FREIRE, Paulo. Pedagogia do Oprimido. São Paulo: Paz e Terra, 1993.

FREIRE, Paulo. Pedagogia da Esperança. Rio de Janeiro: Paz e Terra, 1994. 